\title{
DTPA Captopril Renogram: Still an Invaluable Tool for Probability Assessment in Suspected Cases of Renovascular Hypertension
}

\author{
${ }^{1}$ Nasreen Sultana, ${ }^{1}$ Shamim M F Begum, ${ }^{1}$ Rahima Parveen, ${ }^{1}$ Azmal Kabir Sarker, ${ }^{1}$ Pupree Mutsuddy and \\ 1 Md. Saiful Islam, ${ }^{2}$ Amardeep Chaudhary \\ ${ }^{1}$ National institute of Nuclear Medicine \& Allied Sciences, BSMMU Campus, Shahbagh, Dhaka \\ 2 International Atomic Energy Agency Fellow
}

Correspondence Address : Dr. Nasreen Sultana, Associate Professor, National Institute of Nuclear Medicine \& Allied Sciences, BAEC, Dhaka.

E mail : nasreeninm@yahoo.com

\begin{abstract}
Background: Renovascular hypertension is a secondary form of hypertension which occurs due to renal artery stenosis and is potentially curable. The gold standard for diagnosis of this condition is renal angiography which is rather invasive. Captopril renography on the other hand is an established technique used for more than three decades for accurate and non-invasive diagnosis of significant renovascular hypertension. At NINMAS captopril renography is also used to screen renovascular hypertension and has been a routine procedure since the mid- nineties.

Aim: The aim of the present study is to reassess the value of captopril renography test after two decades of its use at NINMAS.

Materials and Methods: This is a retrospective study of patients who underwent DTPA Captopril renography for evaluation of renovascular hypertension at the National Institute of Nuclear Medicine and Allied Sciences (NINMAS). Divisional archive was searched and patient's clinical record files were screened from January 2014- September 2015. In total thirty patients who had both baseline and post Captopril renography test during this period were selected and analyzed for the study.

Results: Total 30 patients (male 21 and female 09, mean age $24 \pm 5.5$ years); were analyzed who completed both post Captopril and base line studies in two different days. The records showed that a baseline renal scintigraphy was performed with 370-444 MBq Tc-99m diethylene triamine pentaacetic acid (Tc-99m DTPA renogram). Scintigraphy was repeated within a week with $25-50 \mathrm{mg}$ of oral Captopril given $60 \mathrm{~min}$ prior to the test. Among the 30 patients studied, normal post-captopril renogram was revealed in $08(26 \%)$ cases, abnormal findings in $12(40 \%)$, the study was not sensitive in $06(20 \%)$ due to gross parenchyma impairment (GPI) and no change was found in $\mathbf{0 4}(14 \%)$ cases. On the basis of diagnostic criteria for gradation for renal arterial stenosis in 12 abnormal finding of Captopril study, the findings were, grade- 1 in $06(20 \%)$, grade- 2 in $\mathbf{0 5}(\mathbf{1 7 \%})$ and grade -3 in $01(3 \%)$ cases. After assessing time activity curve, glomerular filtration and renal split function the probability assessment of renal arterial
\end{abstract}

stenosis (RAS) among the abnormal Captopril studies $(n=12)$ were determined and the high probability for RAS was found in $05(42 \%)$, indeterminate in $03(25 \%)$ and low probability in $04(33 \%)$ cases.

Conclusion: Captopril renography is a sensitive test for detection of RVH in patients in whom the renal function is as yet unimpaired. Even though our study is severely limited by the lack of confirmatory renal angiogram data, yet we can conclude that captopril renogram by itself is of considerable value since it can predict the functional significance of the stenosis. Therefore we conclude that captopril renography can add value to the diagnosis of $\mathrm{RVH}$ and should remain a method of choice even in this era of Doppler Ultrasound.

Key Words : Captopril renogram, Renal Artery Stenosis (RAS)

\section{INTRODUCTION}

Renovascular hypertension affects 15\%-30\% of patients who have clinical criteria suggestive of renovascular disease. Noninvasive screening is crucial for patient selection prior to conventional angiography and renal revascularization. Renal scintigraphy has been reported to be sensitive for detection of renovascular hypertension, but some of its limitations (eg, in the setting of bilateral renal artery stenosis and renal failure) should be considered. Doppler ultrasonography (US) allows direct evaluation of the renal arteries as well as transrenal Doppler waveform analysis, but it remains operator dependent.

Renovascular hypertension (RVHT) denotes nonessential hypertension in which a causal relationship exists between anatomically evident renal arterial occlusive disease and elevated blood 
pressure (1). The scintigraphic evaluation of renovascular hypertension is best performed in patients having moderate to high risk contributory factors. The risk factors include: a diastolic blood pressure greater than $95 \mathrm{~mm} \mathrm{Hg}$ in a patient that is refractory to 3 anti-hypertensive medications; accelerated or abrupt onset of hypertension; sudden loss of previous hypertension control; impairment in renal function following captopril administration, angiotensin converting enzyme inhibitors, or angiotensin receptor blockers; or an abdominal bruit (2). In patients with renovascular hypertension, the administration of an angiotensin converting enzyme inhibitor will induce decreased tracer uptake or delayed excretion with cortical retention on the affected or both sides. Time-activity curves reveal these alterations in renal function (3). A positive ACE inhibition scintigraphy exam indicates that RVH is present and implies the existence of hemodynamically significant renal artery stenosis (greater than 60 to $75 \%$ of the lumen). The main benefit of the nuclear renovascular hypertension exam is to determine which patients can be expected to demonstrate improvement in blood pressure control following revascularization. The positive predictive value for clinical improvement in hypertension following revascularization, which varies between $51 \%$ to $100 \%$ (mean $85 \%$ ) $(4,5)$. In patients who do not have RVH due to RAS, the time activity curves of pre and post Captopril renogram are similar, since GFR of each kidney remains unchanged.

\section{PATIENTS AND METHODS}

This is a retrospective study of patients who underwent DTPA Captopril renography for evaluation of renovascualr hypertension at the National Institute of Nuclear Medicine and Allied Sciences (NINMAS). Divisional archive was searched and patients' clinical record files were screened from January 2014- September 2015. In total thirty patients who had both base and Captopril renography test during this period were selected and analyzed for the study.
Protocol \& analysis of Captopril renogram:

In Captopril renogram it is important that subjects are well hydrated before the exam. He or She will need to drink at least one liter of fluid within an hour before the study. However, it is also important that patients do not eat for at least four hours prior to the Captopril test. Some medications need to stop prior to the test, such as angiotensin II blockers and ACE inhibitors (at least 24 hours to 7 days, depending upon the conditions).

In post captopril study, before giving the Captopril baseline blood pressure was recorded and Captopril was given orally ((Children: $0.5 \mathrm{mg} / \mathrm{kg}$, maximum 25 mg, Adults: $25-50 \mathrm{mg}$ orally 1 hour before study). After giving captopril, patient's blood pressure and pulse were monitored and recorded in every 15 minutes for next one hour. Tc-99m DTPA renogram was performed using 370-444 $\mathrm{MBq}$ of tracer for adults, up to $74 \mathrm{MBq}$ for pediatric patients. Dynamic images in frame mode were obtained using single detector placed posterior to the supine patient in a dual head SPECT (Siemens E-cam) of an area extending from pubis to xiphisternum. A low energy general purpose collimator was used. Energy peak was set at $140 \mathrm{KeV}$ with a $15 \%$ window. A $64 \times 64$ matrix size was used where zoom was 1.0. Immediately after intravenous bolus administration of radiotracer a total of 60 frames, each being 3 sec/frame were obtained followed by another 27 frames, each being $1 \mathrm{~min} /$ frame. Total acquisition time was $30 \mathrm{~min}$. Baseline study also done in same protocol without captopril. For the renogram evaluation, the nuclear medicine physicians had at their disposal the sequential renogram images, renogram curves and the value of such variables as fractional uptake,time intervals, total counts and integrated counts at different time intervals. Their conclusions were based on visual interpretation as well as on three well-established criteria for diagnosing RAS as formulated for a post-captopril DTPA renogram (6). 
Diagnostic Criteria Based upon Evaluation of the

Renogram Curve: (RD Lele, 2008)

- $\quad$ Grade 0 - Normal curve pattern.

- $\quad$ Grade 1 - Mild delay in upslope with maximal activity seen between 6 and 11 minutes, or delay in the excretory phase.

- $\quad$ Grade 2 - Delay in the upslope and Tmax, but an excretory phase is still seen.

- $\quad$ Grade 3 - As above, but without an excretory phase

- $\quad$ Grade 4 - Renal failure with measureable uptake

Positive Exam: Deterioration in grade following captopril administration is deemed high probability of renal artery stenosis, no change in grade (except grade

0 ) as indeterminate, and improvement in grade as low probability of renal vascular hypertension. Some consider no change in grade for a grade 1 curve as low probability for $\mathrm{RVH}$.

\section{RESULTS}

A total thirty (30) were analyzed who completed both post Captopril and base line study. Among the study subjects male $(n=21)$ \& female $(n=09)$ in number. Mean age 24 5.5 years. After post processing the dynamic renogram study revealed that normal Captopril renogram findings in 08(26\%), abnormal findings in $12(40 \%)$,study not sensitive in $06(20 \%)$ due to gross parenchyma impairment (GPI) and no change in 04(14\%) cases (Table 1). On the basis of diagnostic criteria for gradation for renovascular hypertension there were 12(40\%) abnormal finding of Captopril study. Out of them, grade- 1 in $06(20 \%)$, grade- 2 in $05(17 \%)$ and grade -3 in $01(3 \%)$ cases (Table 2). After assessing time activity curve, glomarular filtration and renal split function, the probability assessment of renovascular hypertension in abnormal Captopril study $(n=12)$ were -high probability for RAS was found in 05(42\%), indeterminate in 03(25\%) and low probability in $04(33 \%)$ (Table 3 ).
Table 1: Overall finding after baseline \& postcaptopril study

\begin{tabular}{|l|c|}
\hline Findings & $\begin{array}{c}\text { Number ( percentage ) } \\
30(100 \%)\end{array}$ \\
\hline Normal & $08(26 \%)$ \\
\hline Abnormal & $12(40 \%)$ \\
\hline Not sensitive due to GPI & $06(20 \%)$ \\
\hline No change & $04(14 \%)$ \\
\hline
\end{tabular}

Table 2 : On the basis of diagnostic criteria for gradation for reno-vascular hypertension

\begin{tabular}{|l|l|}
\hline Grade -0 (Normal curve pattern) & $\begin{array}{l}\text { Number } \\
\text { (percentage ) } \\
08(26 \%)\end{array}$ \\
\hline $\begin{array}{l}\text { Gradc -1 (Mild dclay in upslope with } \\
\text { maximal activity seen between 6 and 11 } \\
\text { minutcs, or dclay in the cxcretory phasc) }\end{array}$ & $06(20 \%)$ \\
\hline $\begin{array}{l}\text { Grade-2 (Delay in the upslope and } \mathrm{T}_{\max }, \\
\text { but an excretory phase is still seen.) }\end{array}$ & $05(17 \%)$ \\
\hline $\begin{array}{l}\text { Grade-3 (As above, but without an } \\
\text { excretory phase) }\end{array}$ & $01(3 \%)$ \\
\hline
\end{tabular}

Table 3: The probability assessment of renovascular hypertension in abnormal Captopril $\operatorname{study}(n=12)$

\begin{tabular}{|l|c|}
\hline Probability & $\begin{array}{c}\text { Number (percentage) } \\
12(100 \%)\end{array}$ \\
\hline High Probability & $05(42 \%)$ \\
\hline Indeterminate probability & $03(25 \%)$ \\
\hline Low Probability & $04(33 \%)$ \\
\hline
\end{tabular}

\section{DISCUSSION}

In the work-up of hypertensive patients in whom a diagnosis of renovascular hypertension is suspected, Captopril renography alone or a paired study (combination with a baseline investigation) is considered to be an essential diagnostic test. Different renographic studies use different criteria to define a positive test or do not define such criteria at all (7). Apart from renographic patterns (the so called visual interpretation), the most widely used scintigraphic parameters in renogram are uptake, time-to-peak, peak activity and residual activity $(8,9)$. Here we did analysis retrospectively this small number patient with suspected renovascular hypertension. Findings were classified on the basis of RD Lele guideline (10). Thus, considerable variability may exist in the 
interpretation of test results and accuracy may not always be definite.

\section{CONCLUSION}

Captopril renography is a sensitive test for detection of $\mathrm{RVH}$ in patients in whom the renal function is as yet unimpaired. Even though our study is severely limited by the lack of confirmatory renal angiogram data, yet we can conclude that captopril renogram by itself is of considerable value since it can predict the functional significance of the stenosis. Therefore we conclude that captopril renography can add value to the diagnosis of RVH and should remain a method of choice even in this era of Doppler Ultrasound.

The limitation of the study is the lack of follow up of the study subjects and the absence of renal angiography to substantiate the Captopril renography findings.

\section{ACKNOWLEDGEMENTS}

The authors very much grateful and thankful to Prof. Lutfun Nisa for her continual support and guidance for writing this article.

\section{REFERENCES}

1. Claveau-Tremblay R. False-Positive Captopril Renography in Patients Taking Calcium Antagonists. J Nucl Med 1998; 39:1621-26.
2. Taylor A. Consensus Report on ACE Inhibitor Renography for Detecting Renovascular Hypertension. Radionuclides in Nephrourology Group. Consensus Group on ACEI Renography. J Nucl Med 1996;37(11):1876-82.

3. Picciotto G, Sargiottoet A, Petraruloal M, Rabbia C, Filippi $\mathrm{P}$ et al. Reliability of Captopril Renography in Patients Under Chronic Therapy with Angiotensin II (AT1) Receptor Agonists. J Nucl Med 2003;44:1574-81.

4. Boubaker A, Prior JO, Meuwly JY, et al. Radionuclide Investigations of the Urinary Tract in the Era of Multimodality Imaging. J Nucl Med. 2006 ;47(11):1819-36.

5. Krijnen P, Oei H, Claessens R, Roos J, Jaarsveld B, J. Habbema B et al. Interobserver Agreement on Captopril Renography for Assessing Renal Vascular Hypertension. J Nucl Med 2002;43:330-37.

6. Soulez G, Oliva V, Turpin S, Lambert R, Viviane Nicolet et al. Imaging of Renovascular Hypertension: Respective Values of Renal Scintigraphy, Renal Doppler US, and MR Angiography. Radiographics 2000;20:1355-68.

7. Datseris IE, Bomanji JB, Brown EA, et al. Captopril Renal Scintigraphy in Patients with Hypertension and Chronic Renal Failure. J. Nucl. Med. 1994; (35):251-54.

8. Diagnosis of Renovascular Hypertension with ACE Inhibition Scintigraphy DOI: http://dx.doi.org/10.1016/S0720-048X(98)00079-5

9. Fakianakis S, George N. Cavagnaro F, Strauss J, Bourgoignie J, et al. Scintigraphy in Acquired Renal Disorders. Ed. Freeman LM. Raven Press, Ltd. New York. Nuclear Medicine Annual 1992; (S)157-224.

10. RD Lele. Principles and Practice of Nuclear Medicine \& Correlative Medical Imaging. Jaypee, 2008:295-301. 